\title{
Decision making processes underlying avoidance of mandatory child vaccination in Croatia - a qualitative study
}

\author{
Helena Tomljenovic ${ }^{1}$ (D) $\cdot$ Andreja Bubic ${ }^{2}$ (D) $\cdot$ Darko Hren $^{2}$ (D) \\ Accepted: 9 October 2020 / Published online: 13 October 2020 \\ (C) Springer Science+Business Media, LLC, part of Springer Nature 2020
}

\begin{abstract}
Despite extensive research evidencing child vaccination is safe and effective, we are witnessing a trend of increasing vaccine hesitancy which is listed among the top ten global health threats. Although some countries incorporate mandatory vaccination programs, no particularly efficient strategies for addressing vaccine avoidance have so far been identified. Within this study we investigated perceptions and reasoning of vaccine hesitant parents from Croatia where child vaccination is mandatory. The aims were to reveal different strategies by which they avoid mandatory vaccination schedules and hypothetical situations in which they would reconsider vaccinating, as well as to identify features of related decision-making. We conducted 25 semi-structured interviews with vaccine hesitant parents and analyzed the data using the framework of thematic analyses. The identified themes were related to the parents' decision-making process, reflection as well as justification of their decision, avoidance behavior of mandatory vaccination schedules and related consequences, dealing with outcomes of the decision and reconsidering vaccinating. The results support and extend previous findings regarding vaccine reasoning, linking hesitancy with the experientially intuitive thinking style and social intuitionist model of moral reasoning. The findings provide important insights into vaccination avoidance and potential for reconsideration, as well as dealing with related risks. Furthermore, we offer a general framework as well as practical guidelines that may help the development of strategies aimed at increasing vaccination rates.
\end{abstract}

Keywords Vaccine hesitancy $\cdot$ Vaccine decision-making $\cdot$ Avoiding vaccination $\cdot$ Moral foundations theory $\cdot$ Experientially intuitive thinking style

\section{Introduction}

Child vaccination is highly effective in reducing the incidence of a range of infectious diseases as well as reducing associated morbidity and mortality (Caron-Poulin, Rotondo, Cutler, Desai, \& Squires, 2017), making programs aimed at child vaccination a crucial component of global public health strategies. However, despite the large body of evidence showing that child vaccination is both safe

Electronic supplementary material The online version of this article (https://doi.org/10.1007/s12144-020-01110-7) contains supplementary material, which is available to authorized users.

Helena Tomljenovic

helena_tomljenovic@hotmail.com

School of Medicine, University of Split, Split, Croatia

2 Chair for Psychology, Faculty of Humanities and Social Sciences, University of Split, Split, Croatia and effective, vaccination coverage rates do not always meet the rates necessary for herd immunity suggested by the World Health Organization (WHO) (Adams et al., 2015). For example, reports indicate that, in 2017, in Europe 23,927 people were infected with measles, with at least 35 associated deaths, which represents a fourfold increase in relation to the previous year (WHO, 2018a). Even more alarming rates are reported for 2018, indicating more than 41,000 were infected in the first 6 months (WHO, 2018b). It is therefore not surprising that vaccine hesitancy, a phenomenon that includes a spectrum starting with refusing all, continuing with accepting some while refusing other vaccines and ending with acceptance of all vaccines, is listed among top ten global health threats in 2019 (WHO, 2019). Given the societal relevance of this topic, there is a growing interest in investigating factors underlying this hesitancy. Research addressing this topic has indicated the importance of different psychological, cultural and societal factors which contribute to both developing 
and maintaining vaccine hesitancy (Conis, 2015; Gilkey et al., 2014; Gust et al., 2005; Prislin, Dyer, Blakely, \& Johnson, 1998; Taylor et al., 2003). One general feature which can be related to some individuals and which seems to make them vulnerable to developing hesitancy is the mistrust towards vaccines (and anything related to it) that leads to the phenomenon often referred to as the vaccine-confidence gap or the crisis of public trust (Larson, Cooper, Eskola, Katz, \& Ratzan, 2011). With respect to general public trends, another interesting phenomenon occurs in countries where vaccination schedules are well-established, in which immunization becomes a "victim of its own success', in a way that people do not have the direct experience with infectious diseases as they did before (Dube, Vivion, \& MacDonal, 2015). Therefore, some individuals develop a fear of vaccine side-effects which is stronger and more prominent than the fear of vaccine-preventable diseases, which then in turn leads to avoidance of vaccines. Besides this general tendency, different specific parental personal characteristics were also associated with hesitancy (Adams et al., 2015; Brown et al., 2010) suggesting the complexity of the related decision-making process which is influenced by various factors, including emotional, cultural, spiritual, political, and cognitive ones (Dube et al., 2013; Hobson-West, 2003; Streefland, Chowdhury, \& Ramos-Jimenez, 1999). First, vaccine hesitant parents more often subscribe to natural parenting and philosophies (Gullion, Henry, \& Gullion, 2008; Omer, Slamon, Orenstein, deHart, \& Halsey, 2009; Prislin, Suarez, Simpton, \& Dyer, 1998; Smith, Chu, \& Barker, 2004; Wei, Mullooly, Goodman, et al., 2009), and have a belief system that diverges from the traditional biomedical paradigm (Cruz Piqueras, Rodriguez Garcia de Cortazar, Hortal Carmona, \& Padilla Bernaldez, 2017). They also have less confidence in their physicians, are often dissatisfied with given information (Brown et al., 2010), believe governments or big-pharma are not trustworthy (Gardner, Davies, McAteer, \& Michie, 2010), and are more likely to use alternative medical services like homeopathy and naturopathy (Benin, Wisler-Scher, Colson, Shapiro, \& Homlboe, 2006). Next, they more often think of the vaccination risks as larger than those of diseases and less frequently consider vaccines as effective (Brown et al., 2010; Mills, Jadad, Ross, \& Wilson, 2005). They do not believe that infectious are serious (Brown et al., 2010; Mills et al., 2005) and believe their children are at less risk of being infected (Brown et al., 2010; Falagasa \& Zarkadouliaa, 2008; Mills et al., 2005). Parents who are less likely to vaccinate are also more concerned about side-effects (Brown et al., 2010; Falagasa \& Zarkadouliaa, 2008; Mills et al., 2005) and rely on anecdotal and personalized experience (Blaisdell, Gutheil, Hootsmans, \& Han, 2015). Furthermore, they show bias to omission over commission, more frequently perceive that they can control the child's susceptibility to diseases, as well as their outcomes (Meszaros et al., 1996), and believe it is better to acquire immunity from getting infected than from getting vaccinated (Meszaros et al., 1996; Salmon et al., 2005). Finally, they are more likely to fear harming their child (Salmon et al., 2005), are prone to the so called free-riding effect reflected in the fact that they feel that their own children are not at risk of infection because others are vaccinating theirs (Hershey, Asch, Thumasathit, Mezaros, \& Waters, 1994; Meszaros et al., 1996), and fear too many vaccines are dangerous (Gellin, Maibach, \& Marcuse, 2000; Salmon et al., 2005).

Even though there is extensive research on determinants of vaccine hesitancy, until today completely efficient ways to address vaccine hesitancy and avoidance have not been identified (Jarrett, Wilson, O'Leary, Eckersberger, \& Larson, 2015). One strategy that improves compliance to vaccination programs is mandatory vaccination, but reports show a great variation and diversity between countries regarding the implemented strategies (Bozzola et al., 2018; Haverkate et al., 2012). For example, nine countries in Europe have mandatory immunization schedules for measles, mumps, rubella, dhyptheria, tetanus, HiB, pertussis, hepatitis B and poliovirus, whereas for 21 countries such vaccination is either recommended, recommended only for specific groups, or not recommended (Bozzola et al., 2018). One of the nine countries which adopts such mandatory vaccination schedules is Croatia where child vaccination is free of charge, provided by various healthcare professionals including GPs, pediatricians, epidemiologists and others who are all by law obliged to take part in the vaccination. If they refuse a vaccine for their child, the parents are then referred to epidemiological counselling and can be reported to other institutions within the Ministry of Health and financially fined (ECDC, 2015). Despite such compulsory vaccination politics, infectious outbreaks still occur and there seems to be a gap in literature which would explain why such endeavors are failing and address behavioral strategies that vaccine hesitant parents use in order to avoid mandatory immunization. Related to this, not much is known about certainty of parental decision about not vaccinating, as well as factors that may motivate parents to reconsider their decision. Building on that, this study's general aims were to first investigate cognitive processes underlying vaccine hesitant parents' decision making, specifically focusing on hypothetical situations in which they would reconsider vaccinating, and, second, to investigate their behaviors and strategies by which they avoid mandatory vaccination and deal with potential consequences. By doing so, this study, to our knowledge, represents the first to investigate strategies of avoiding mandatory vaccination. Therefore, this research may uniquely contribute to the existing literature by providing useful insights into this matter. Gaining understanding of these factors might also be of importance for guiding the development of strategies aimed at increasing vaccination rates. 


\section{Methods}

\section{Participants}

We included Croatian parents or caregivers with at least one child for whom they refused all or parts of mandatory vaccinations or changed or intend to change their children's routine vaccine schedule, and who agreed to participate in this study. We excluded people without children, parents who accept standard vaccine schedules, and those who refused to participate. A total of 25 parents/caregivers (4 male and 21 females; of average age 37 years [total range 27-50]) participated in the present study. Two participants were married to each other, while others were not members of the same family. Other socio-demographic information is presented in Table 1. Their children were of 3 months to 15 years of age. There were also notable variations among the participants in vaccine uptake. For example, sometimes the oldest child received all mandatory vaccines or all vaccines up to an age, while the youngest received one or no vaccines. Three participants refused all vaccinations for all their children, and children of six participants received the first vaccine given within the maternity ward and none of the later ones.

\section{Materials}

The semi-structured interviews were conducted following a Topic guide (Appendix 1) and socio-demographic questionnaire, which were developed with regard to relevant literature, study aims, and pragmatist epistemological approach following the principle of basing the enquiry in human experience (Brierley, 2017), as it is of interest in this study to describe the participants lively and subjective experiences. The sociodemographic questionnaire collected basic information pertaining to the participants (age, education, level, marital, employment status, political and religious orientation), and information regarding their vaccination schedule so far, namely the list of vaccination their children were given, and which they refused or delayed. Also, we asked the participants to report if they were aware of a vaccine preventable epidemic in their living area in the past 5 years.

\section{Design}

This study was of a qualitative design, we used a mixed purposeful sampling strategy with the described inclusion and exclusion criteria, through chain/snowball sampling (Patton,
Table 1 Participants' selfreported socio-demographic status

\begin{tabular}{lll}
\hline & & N \\
\hline Level of education & High school & 6 \\
Socio-economic status & University & 19 \\
& Below-average & 2 \\
Employment status & Average & 20 \\
& Above average & 3 \\
Marital status & Employed & 22 \\
& Unemployed & 1 \\
& Parental leave & 2 \\
Number of children & Married & 21 \\
& In a relationship & 2 \\
Political orientation & Divorced & 1 \\
& Single & 1 \\
& One & 11 \\
& Two & 9 \\
& Three or more & 4 \\
& None & 16
\end{tabular}


1990). Sample size in qualitative studies cannot be determined a priori by statistical power or other computations, and no sample size restrictions are imposed as it depends on the nature of the phenomenon investigated. However, for interview studies it is not recommended to include more than 50 participants (Sandelowski, 1995). Therefore, the sample size was aimed to ensure the saturation of themes, meaning new participants were recruited until no new relevant codes could be identified, and when the identified codes became well established, demonstrated distinct properties and dimensions, and relationships between codes became clear (Sandelowski, 1995; Strauss \& Corbin, 1998).

\section{Procedure}

Data was collected during September and October 2018. Participants were contacted by an open invitation to participate that was shared on a web portal (www.roda.hr) and social media. The topic guide was first pilot tested on two participants. No adjustments to the topic guide were necessary so other respondents were approached and interviewed using the same protocol. All participants were given an informed consent sheet and explained their rights and the purpose of the study, as well as basic rules of participation. All the interviews were held in an agreed controlled setting between the participant and interviewer with basic training in qualitative research methodology (HT) , supervised by a senior researcher (DH). They were conducted by phone for 23 participants, as it that was more convenient for them. There was no third person present during the interviews, except for four participants where the parent's child was present in the background. The interviews were audio recorded using an audio recording device or phone call recorder, and verbatim transcribed by a voice recognition software (Google speech to text) in preparation for analysis. All transcripts were double-checked and appropriately corrected in relation to audio recordings. Notes related to the content and interviewer's reflections were taken immediately after the interviews. Transcripts were de-identified and securely stored. Only the principal investigator had access to the data and the codes that enabled connecting specific transcript to participant's identity. After transcribing, the audio files were deleted. Data analysis started in September 2018, after conducting two pilot interviews and continued until January of 2018. Thematic analysis was used to analyze the transcripts (Braun \& Clarke, 2006). It included developing a preliminary coding framework based on the initial analysis of important themes on the first six interviews. The preliminary analysis was done by HT who read the transcripts and coded the data under the supervision of a senior researcher (DH). The framework was then applied to code the remaining data, after which the codebook was redefined multiple times (Appendix 2). In doing so, it mostly changed in the way that parts of the identified codes were later merged in one code with multiple sub-codes, with the goal of reducing the data in order to make it more manageable. When the final codebook was developed, the final codes were assigned to all upcoming transcripts. To ensure the trustworthiness of the analysis, HT and DH regularly met for consultation, supervision and resolving of other issues. The data was entered into a program specialized for qualitative data analysis, Atlas.ti (version 8). We referred to the standards of reporting developed by O'Brien and colleagues as reporting guidelines (O'Brien, Harris, Beckman, Reed, \& Cook, 2014).

\section{Results and Discussion}

In this study we investigated behavioral strategies of avoiding mandatory vaccination and situations of reconsidering the decision among vaccine hesitant parents, as well as the emotional and justification mechanisms underlying vaccine hesitancy and decision-making. A total of $18.4 \mathrm{~h}$ of audio material was collected, with an average of 44.16 min per interview. The codes which were found during the analysis were divided into broader inter-related themes (Fig. 1; detailed representation of all codes within themes along with related subcodes, all relevant participants' citations under pseudonym and age are available in Appendix 3). Here we discuss individual topics of the interviews in the order they were discussed within the interviews.

\section{Decision-Making on Vaccination and Hesitancy}

Within the first theme we identified several codes related to the vaccine decision-making process, which demonstrated this to be a complex and time-consuming process primarily driven by emotional factors and highly sensitive to social influences and pressures. Participants related emotions and intuition to the fear of side-effects and a strong desire to protect their child, commonly labelling it as 'instinctive', whereas fear of sideeffects and intuitive feelings of 'wrongness' of vaccines emerged as major motivators of avoidance: You get so frightened, it is fear, when you hear all that and see a child with side-effects, you fear it. (Britney, 50); You have like an instinct in you, which tells you, I don't know a way to explain it (Olivia, 30). Although the role of emotions in vaccine uptake has been tackled before (Brown et al., 2010; Chapman \& Coups, 2006), our results expand these findings and suggest the role of emotions in vaccine avoidant behavior is even greater. Given that the emotional system is evolutionary older and has primacy in different ways (Loewenstein et al., 2001), it can further be argued that parents are evolutionarily especially sensitized to perceived threats to offspring, which are emotionally more evoking than other situations. Related to this, previous results have also demonstrated that people in 


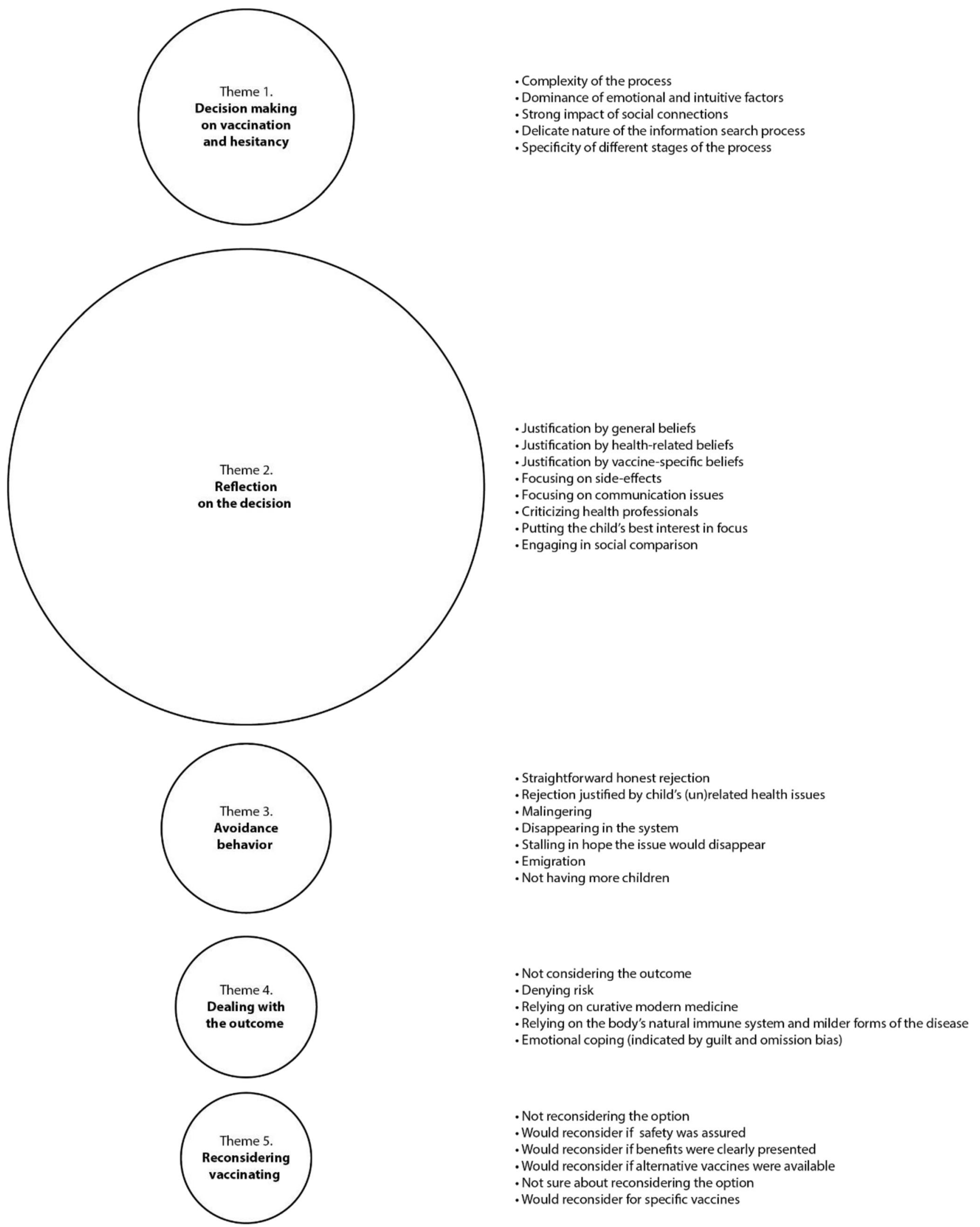

Fig. 1 Identified themes, circle size indicates the frequency in which the participants talked about each theme 
emotionally burdened decision become prone to deviations from rational thinking (Suter, Pachur, \& Hertwig, 2015; Suter, Pachur, Hertwig, Endestad, \& Biele, 2015).

Participants also reported a strong impact of social connections and were very sensitive to different social relationships when making the decision about child vaccination. The importance of social influences in general health behavior is well recognized (Armitage \& Conner, 2000), and our results suggest that parents are primarily sensitive to complex dyadic spouse relations, e.g. a pro-vaccine parent being nudged by their anti-vaccine spouses, as well as the influence of relevant information sources and their doctors. In addition, the social influence on parents may be identified based on the sources of information they rely on. Specifically, the majority of parents searches for information on various anti-vaccine media, which is in accordance with previous findings (Wolfe, Sharp, \& Lipsky, 2002). Interestingly, we found some parents actively seek and read scientifically rigorous reports and papers such as systematic reviews: I have just recently read a report, published in Cochrane in 2017, about the flu vaccine, stating it was ineffective, with very small effect sizes, with lots of sideeffects' and so on (Amanda, 34). This may explain why some hesitant parents hold objectively valid knowledge on vaccines but still refuse to vaccinate (Sobo, 2016), as well as the knowledge-gap based interventions not being particularly effective in reducing hesitancy (Jarrett et al., 2015).

The interviewees also reported different specific stages of the decision-making process. Notably around half of them had initial positive attitudes towards vaccination that changed based on direct experience with child's health issues, especially when these were perceived as side-effects of vaccines, as well as general negative experience with the healthcare system or during child birth, reshaping of priorities and becoming more inclined to a healthy life style, or personally suffering from vaccine related infections. In other words, some parents held initial positive attitudes towards vaccination that were challenged by negative events which raised doubts about vaccines: I was the first to be up for vaccinating, always came early not to miss it (...) after three month she had a rash, atopic dermatitis (...). Should I continue or not...that's when I started thinking. (Anna, 30). Alarmingly, parents also reported unprofessional communication from clinicians, including being ridiculed after asking questions about vaccines. Although disruptive behavior occurs in less than $5 \%$ of workers (Stewart, Wyatt, \& Conway, 2011), it is a recognized issue in health professionals linked to a variety of adverse events (Grissinger, 2017). It is possible to hypothesize some clinicians raise stereotypes and label parents as 'anti-vaxx' and do not invest time and effort in helping to resolve their doubts. This notion also relates to the well-recognized issue of parents' significant dissatisfaction with communication on vaccines (Brown et al., 2010). Apart from such negative experiences with health professionals, experiences with adverse events contingent to time after vaccinating strongly contributed to hesitancy in some participants. Such experiences evoked fear and concern, and further disrupted trust towards health professionals. Specifically, doctors' denial, non-recognition, or non-acknowledgement of the possibility that the vaccination had side-effects led parents to feel like they had no one to rely on and thus have to 'take matters into own hands'.

\section{Reflection and Justification of the Decision Not to Vaccinate}

Justifications and vaccine related beliefs were identified as the most frequent way of reflecting on the decision not to vaccinate, with the largest number of codes (Appendix 3). Applying the line of thinking offered by the social intuitionist model (Haidt, 2001), it may be postulated that parents' intuitions moved them in direction of opposing vaccines, which then motivated justifications of why vaccines are bad (Brown et al., 2010; Chapman \& Coups, 2006). These justification were found to be related to general worldview, moral and religious beliefs: I am not 'a man of the system', I do not follow where others go, and I want to think with my own head and I do not support single-mindedness (Tom, 37); First of all, I am religious, I believe in Jesus Christ (...) (Amanda, 34).

Moreover, in our study notably more than half of the participants also held on to some form of conspiracy beliefs: The more I read about it and the more research I do, I think it is in a way poisoning people. That may sound like a conspiracy theory or something like that, but definitely (Lisa, 27), which are also generally found to be associated with feelings of anxiety (Prooijen \& Douglas, 2018). The presence of emotional, intuitive and conspiracy factors may further be associated with some aspects of the experientially-intuitive style within dualprocessing theories (Epstein, Pacini, Denes-Raj, \& Heier, 1996). This thinking style is opposed to the analytically rational one and is highly emotionally saturated. It is also a key factor in the formation of general conspiracy ideation, as well as specific vaccine conspiracy beliefs (Tomljenovic, Bubic, \& Erceg, 2019). Namely, it is hypothesized that relying on the experiential style makes individuals more susceptible to endorsing statements which are not well thought through. This may occur because the careful and deliberate information processing related to the analytically-rational style, which increases attention to logical flaws and inaccuracies, is overridden by the experiential style (Swami, Voracek, Stieger, Tran, \& Furnhan, 2014). Related to this, Law (2011) explains various ways that lead educated and intelligent people to develop beliefs which are opposed to rationality or science. His examples resonate with research repeatedly showing reasoning in vaccine hesitancy to be burdened with various reasoning flaws (Jacobson, Targonski, \& Poland, 2007). The idea that attitudes 
towards vaccines are based in intuition has been proposed before. For example, a study by Amin et al. (2017) linked vaccine hesitancy to several moral domains proposed by the Moral Foundations Theory within the social intuitionist model which claims that intuitions form the base for moral judgements, and reasoning generally may be viewed as an ex post facto process used to justify those judgements (Haidt, 2001). In that context, Amin et al. (2017) identified that overt parental concerns about vaccines, both their justification and reflections, may be linked to moral domains as described by the this theory. Specifically, they demonstrated that a sense of violation within domains of purity and liberty mediates the relationship between those moral foundation and vaccine attitudes (Amin et al., 2017). They argue that these foundations promote overt vaccines beliefs which are seemingly unrelated to moral domains. An example is the belief that vaccines contain poisons and toxins, whereas diseases represent a natural phenomenon (purity), as well as the belief that mandatory vaccination violates civil liberties under excessive institutional control (liberty). Our findings support this line of thinking as our participants offered their identity relevant values, including worldview, moral, and religious beliefs as a significant trajectory of entering the decision of avoiding vaccination.

In addition to general beliefs, the participants also referred to specific ones regarding parenthood and beliefs related to health. The most frequent codes were related to different beliefs towards immunization or vaccines, tackling almost all its domains. The justifications offered by participants in our study confirmed well documented findings regarding beliefs of vaccine hesitant parents (Downs, Bruine de Bruin, \& Fischoff, 2008; Smith, Amlot, Weinman, Yiend, \& Rubin, 2017; Yaqub, Castle-Clarke, Sevdalis, \& Chataway, 2014) and extend to some specific themes related to the unique position of Croatia to other countries. This is again in accordance with the social intuitionist model, which suggests that reflections rise as ex post facto and are used to justify those previously made judgements (Haidt, 2001). One example is the comparison to other countries which only have recommended, but not mandatory vaccination (Bozzola et al., 2018; Haverkate et al., 2012). This is again related to liberty as a moral domain, as parents argued that such strategies work well in other developed countries, and that mandatory vaccination was a sign of backwardness. Furthermore, they expressed their concerns that lower quality vaccines are imported to Croatia today which was also related to the argument of why they do not want to vaccinate their children even though they were vaccinated themselves. This may be related to various publicly exposed affairs on lower quality of various products, e.g. food or detergents, in Croatia (Boffey, 2017). A next important code focused on vaccine side-effects, pointing to mistrust towards registration and tracking of vaccines, stating that the published rates are not trustworthy. Some mentioned physicians showed different official versus private opinions, which further supported the parents' hesitancy: For me as a lay man, who knows nothing about it, when I hear professionals are not unanimous, to that degree that some do not vaccine their kids... I have a friend who is a doctor of immunology and his wife is a physician too, they did not want to vaccine their kid (Jack, 42). Some of the participants also engaged in social comparison and looked at vaccine attitudes as a social issue that polarizes people into pro or anti vaccine groups and distanced themselves from being a member of either of these. About a half of the participants addressed the issue of publicly declaring their attitudes. For some it represented an intimate and private issue and they were careful when publicly communicating their decision, keeping it secretive, whereas some were especially engaged in civil initiatives to communicate or inform the public about harmfulness of vaccines, which may both serve as an identity protective strategy (Baumeister, Tice, \& Hutton, 1989). Interestingly, some participants who, regardless of being certain in their decision of not vaccinating, still did not declare themselves as antivaccine oriented.

\section{Vaccination Avoidance Behavior}

This study was, to our knowledge, first to investigate different ways by which parents avoid mandatory child vaccination and deal with potential consequences, and the obtained results demonstrate they use several avoidance strategies. These included straightforward rejection, rejection justified by related and unrelated child's health issues, malingering, disappearing in the system, stalling in hope the issue will disappear, emigration and not having more children. The results moreover demonstrated that avoidance was primarily associated with features of the parent and of the appointed clinician, as well as their relationship. Regarding parents' characteristics, these referred to the public disclosure of their attitudes and fear of further consequences. Parents varied in their openness of communicating the decision to clinicians, and some stated they were straightforward and honest in refusing vaccination and communicated it to their health professionals openly:

\section{I did not deceive them. I just said I do not want to vaccinate my second child and I will take responsibility for it. (Jack, 42); I have not been most honest with her (doctor) about it, meaning I did not say I do not want to (vaccinate). (Helen, 31)}

Regarding clinicians' features, these are associated with their degree of tolerance to hesitancy and level of involvement with patient. For a part of the parents, avoiding came easily since their doctor was tolerant to avoidance and cooperative so it led to no further consequences: 
Well, our pediatrician is great. He won't say he is against vaccinating, but he is a reasonable man and he also does not force us (Emma, 33); The same thing happened later with the school doctor who said she has complete understanding for me, and she did not report me, so I have no problems with the system. (Rachel, 37)

In regard to the consequences of avoiding vaccination, some parents experienced being asked to sign an informed consent about the refusal, being referred to a talk with an epidemiologist, or being legally prosecuted, as well as receiving financial fines and not being able to enroll the child into kindergarten:

\begin{abstract}
The first report was at the hospital, I had to sign a paper which said I refuse to vaccinate and that I am informed about the benefits of vaccines (...) after a few weeks, I got a call to go to an informative talk with the epidemiologist, so the doctor can talk to me 'about vaccines' and that I get better acquainted. She turned us in to the sanitary inspector, who is by duty obligated to file a court lawsuit, by which we get a fine, and you can get a fine for every vaccine you decline. (Julie, 38); I can't get my child into kindergarten, because she is not fully vaccinated, and I can't go to work if she is not in kindergarten (Barbara, 31).
\end{abstract}

One mentioned giving instructions to the child about how to avoid the upcoming vaccination at school. Another did not send the child to school on those days and, instead, sent in an excuse notice: When the vaccination was planned in school, I just would not send her to school that day. (Samantha, 46). Parents who did not disclose their opinions openly also seemed to vary in the degree of malingering: some stalled on behalf of the child's health issues, acute or chronic, objective or subjective, which was mostly accepted by clinicians and led to no further actions, such as muscle hypo- and hypertonia, premature and underweight birth, autism and other developmental difficulties:

He was a neuro-atypical child and the pediatric neurologist did not give permission for the vaccination, we had to ask for her medical opinion first, and she said, 'better not', so the vaccine was avoided. (Sofia, 37); I wanted to postpone the vaccination because I believe my child has a weaker immune system. She reacts to food quite bad, (...) has rashes, diarrhea, vomits (...). But my doctor doesn't want to hear about it because she doesn't think it is any kind of an acute condition, and there is no reason not to vaccinate. (Julie, 38)

A few obtained medical opinions from doctors stating the child should be exempted from further vaccination. One mentioned not being truthful and stalled claiming their child might suffer from allergies:

No one is forcing us now. They have taken into consideration the medical document which we obtained from a psychiatrist about the exemption. So, I do not have a problem with it anymore. (Jessica, 40); Actually, we said that we have allergies in our family and that we wanted to wait and see what happens when he starts eating food and he actually started getting these rashes, so the doctor said 'ok, let's wait for a year' but he still had those. When he was two years old, we made an allergy test, and nothing was found. The doctor said we can decide if we want to vaccinate. (Sara, 36)

The next strategy included stalling and avoiding contact with the clinicians, ignoring calls, going to a private clinic, or transferring to a less strict physician: When I would go to the doctor, he said let's make a date. I said ok, when the child feels better. He would get better, and I did not show up. (Emma, 33); I did not go to that doctor anymore and did the check-ups in a private polyclinic. (Jennifer, 41); Of course, I asked around, I was told she (the new doctor) would not condition the vaccination and she would understand us. Even if I have to travel further for the check-ups because it is out of the city. It is not a problem; I would do everything for my son's best interest. (Jennifer, 41).

Some also mentioned second-hand experience of malingering, bribery, deceits or adulteration of medical records:

Most parents actually lie to their pediatrician and try to postpone vaccinating. (...) Some parents are desperate (...), desperate to such a degree they forge their vaccination medical documentation, just so their child could get into kindergarten. Lisa, 27); You can go to a second pediatrician, pay her something, she gives you the certificate so you can get the children into kindergarten. (Tom, 37).

Next, some explained that they managed to avoid vaccination due to oversights within the healthcare system, e.g. due to child's doctor retiring or generally being in good health and not seeing the doctor often. This strategy allowed them to avoid vaccination without being officially prosecuted because of their refusal:

When I contacted the pediatrician regarding my first child, they would ask 'what about the other child, when will we vaccinate her, here is your date so come and vaccinate', I said 'fine' but did not show up. (Barbara, 31); They are quite healthy, so we do not go to the doctors' often. (Emma, 33); Well, we were in a kind of a grey area. We changed the doctor, the other one 
retired, as so on; we kind of did not get into the system.

(Franck, 42)

Finally, two participants stated they knew people for whom mandatory vaccination was a motive for moving out of Croatia and one participant expressed unwillingness to have a second child because of mandatory vaccination and the necessary struggle to avoid it:

\begin{abstract}
A lot of people leave here because of it. That is certainly not the only reason but those who are a bit more open or alternative; they just pack and move to a country where they won't have problems with it. (...). I think it is a torturous issue here in Croatia, and for young people who do not want to vaccinate their children, I think it is hard. (...). I know such people, who moved to Germany. They did not want to be bothered with it the whole time; they just did not want to. I know two families who moved. (Sara, 36); For example, for this reason I do not want to have a second child. The reason is that I do not have the will for the fight. (Lisa, 27)
\end{abstract}

Altogether, these results demonstrate avoidance strategies are related to some features of the appointed clinician and further corroborate an important role of health professionals in addressing hesitancy (Dube, 2017; ECDC, 2015; Peterson et al., 2016). Our results suggest that some clinicians tolerate, or even share parents' vaccination hesitancy or have loose relationships to their patients which then contributes to easier avoidance. Vaccine hesitancy among healthcare workers is a recognized but under investigated issue, as the proportion of hesitant healthcare workers remains unknown (ECDC, 2015) despite evidence suggesting that some are against vaccines and have concerns about the related risks and a lack of trust in health authorities (ECDC, 2015). Specifically, within a broader European qualitative study on vaccine hesitancy, healthcare workers interviewed in Croatia reported a need for improving their training about vaccines and better communication with patients. In the same study, a minority of the interviewees reported not feeling comfortable addressing vaccine hesitancy and sharing the same doubts about vaccine as parents do. Therefore, avoidance strategies used by parents may be directly related to the communication skills and attitudes towards vaccination of healthcare workers. Parents whose clinicians did not support or ignored their avoidance used malingering or open conflict with clinicians as strategies of avoiding vaccination. Generally, healthcare workers should develop a relationship of trust and stronger bonds with the patients which would provide a safe environment to discuss various issues related to vaccine hesitancy and prevent parents disappearing in the system or malingering.

\section{Dealing with the Outcome and Reconsidering Vaccination}

When asked how they cope with the risk of their child being infected with a disease, several participants seemed to lack any strategies of dealing with the risk and reported they have never so far considered it, therefore displaying only vague strategies related to this issue. A generally common finding is that vaccine hesitant parents do not perceive infectious diseases and related risks as serious (Brown et al., 2010; Mills et al., 2005) and our results support these findings further demonstrating that this also reflects on dealing with the risk of infections. Alarmingly, some never even considered such a risk or again insisted that vaccines are the source of diseases, thereby denying the possibility of infection: I honestly do not know, I will think about it when it happens, why would I even imagine that, what for. (Samantha, 46); I am quite certain vaccinating is one of the main things contributing to infection. $(J o h n, 45)$. Next, some stated that they would rely on modern medicine, claiming it would be easy to find a way of successfully treating the infection if it emerged: Well I think today's medicine has a solution for that. (Frank, 42). The participants most frequently stated that they relied on keeping the body and immune system strong and believed that their child could only be infected with a milder form of the disease:

Well then, he would probably get a milder type, because my child has recovered from all the usual childhood diseases, which were all in their mildest form (...) because of his good immune system and his health condition. (Sofia, 37)

Some have compared vaccinated and non-vaccinated children, stating the non-vaccinated are, generally, in much better health: There was a German study which showed that nonvaccinated children are 500 times healthier than vaccinated ones. (Tom, 37). Finally, a couple stated that they would feel very guilty in case of child's disease, and a few showed omission bias, which both indicated emotional coping:

If they got infected with, I don't know, polio or something (...) I would like to kill myself, figuratively speaking, it would be awful. But also, it would be awful if I vaccinated them and something happened, I don't know which is worse. (Jack, 42)

Finally, participants also differed in the determination on their decision on vaccinating and reconsidering vaccinating. Some stated they are certain they will not vaccinate anymore: In nothing in life am I so determined as in the decision not to vaccinate my child...I have no doubts at all. (Helen, 31), and a couple did not know - implying they were still in the decisionmaking process. Those who were willing to reconsider 
mentioned that they would do so only under specific conditions which might be beneficial in tailoring interventions aimed at promoting vaccination rates (discussed later), e.g. being given absolute assurance on safety, having benefits be clearly presented to them or having alternative vaccines available:

\section{If someone guaranteed to me 'it is $100 \%$ safe', like my mom told me that things were for her generation. She was told by the pediatrician it comes in such small doses, it has no side effects, your child will be protected from this and that', and my mom knew that was it, she heard about no case reports, anything disputable, then I would accept it too, and I would love it if that were the case today as well. (Nancy, 29); If there was something which would explain it all in a compelling way, like in a book, YouTube video, documentary or whatever, if someone explained why we should vaccinate against this disease, why one should vaccinate, I would do it, I have nothing against rational arguments, although they also do not have to mean anything (...) (Jack, 42); I am for the option of paying for vaccines, if I could choose which I want, which is of more quality, in that case I might vaccinate. (Pamela, 30).}

Some did not refer to reconsidering the decision but mentioned they might vaccinate for specific diseases, namely tetanus and those present in distant areas, if they travelled there, which further supports the notion that hesitant parents do not perceive common infectious diseases, such as measles, as dangerous (Brown et al., 2010; Mills et al., 2005) and that they attribute threat to specific diseases or those uncommon to the area where they live:

If I were to travel to, let's say India or a distant country, the South African Republic, or somewhere where conditions of life are different then here, I think I would vaccinate my child against some diseases which we do not face here. (Britney, 50)

\section{Unifying the Relevant Vaccination Avoidance Themes}

With regard to the emerged data, we have developed a graphical representation of the themes identified in the interviews: reflection of the decision, decision-making on vaccination and avoidance, reconsidering vaccinating, dealing with the outcome and avoidance behavior. We propose this as a speculative model based on authors' interpretation of the meanings of identified themes and its associations (Fig. 2). The themes are arranged in a set of tentative relationships, whereby the circle sizes represent relative frequencies of identified themes, while full arrows indicate direct and broken arrows potential or probable influences between them.

As presented in Fig. 2, we suggest that Decision making is directly related to Reflection on the decision as a two-way feedback loop where the decision feeds into the reflection, but reflection also feeds into the decision. The relationship between the Decision making and the Avoidance behavior goes only one-way, i.e. decision leads to the behavior. We are aware of a long tradition of research within social psychology indicating changes in cognition due to behavior (Aronson, Wilson, Akert, \& Sommers, 2015). However, in the case of vaccination the decision must come first, although we do not argue that it needs be rational or even a conscious one. Once behavior is executed it can lead to further reflection (or rationalization), thus closing the loop. It can also lead to Dealing with the outcome (of non-vaccinating), real or imagined, which can, in turn lead to Reconsidering vaccination and/or Reflection on the decision. All that can subsequently inform Decision-making and lead to the new decision-reflectiondecision-behavior loop.

As mentioned, we believe that the frequency in which the specific themes emerged at least in part indicate the relative importance that theme holds for the participants and its' relative contribution to hesitancy. Although it could be argued that the presented themes were evoked by pre-defined questions from the topic guide and that the frequencies primarily reflect the questions that were asked, we believe this may only be true to a certain degree. Specifically, although we did bring the mentioned themes to the participants, the semi-structured nature of the interviews allowed them to remain in the topics for as long as they desired and to take the conversation to different directions. Thus, they were the ones who made the final decision which topics to address in detail, and which more scarcely. For example, even when explicitly asked, respondents gave rather short or vague answers to questions of dealing with the outcome of the decision and generally did not spontaneously verbalize their positions in that regard. Reversely, their reflections on the decision seemed to be well-elaborated indicating that they had considered this issue significantly and argued their positions before. This furthermore indicates that rationalization may be particularly important in vaccine hesitancy, where parents seek justification of their norm-defying decision. Given that the proposed model is based on the authors' interpretation in one study and a very limited data set, it is naturally very tentative and speculative and should be tested in upcoming studies.

\section{Limitations and Directions for Future Research}

While interpreting this study's results, some limitations should be kept in mind. It is worth noting that the interviews were done at one timepoint, and that some participants reported still being in an ongoing decision-making process, 


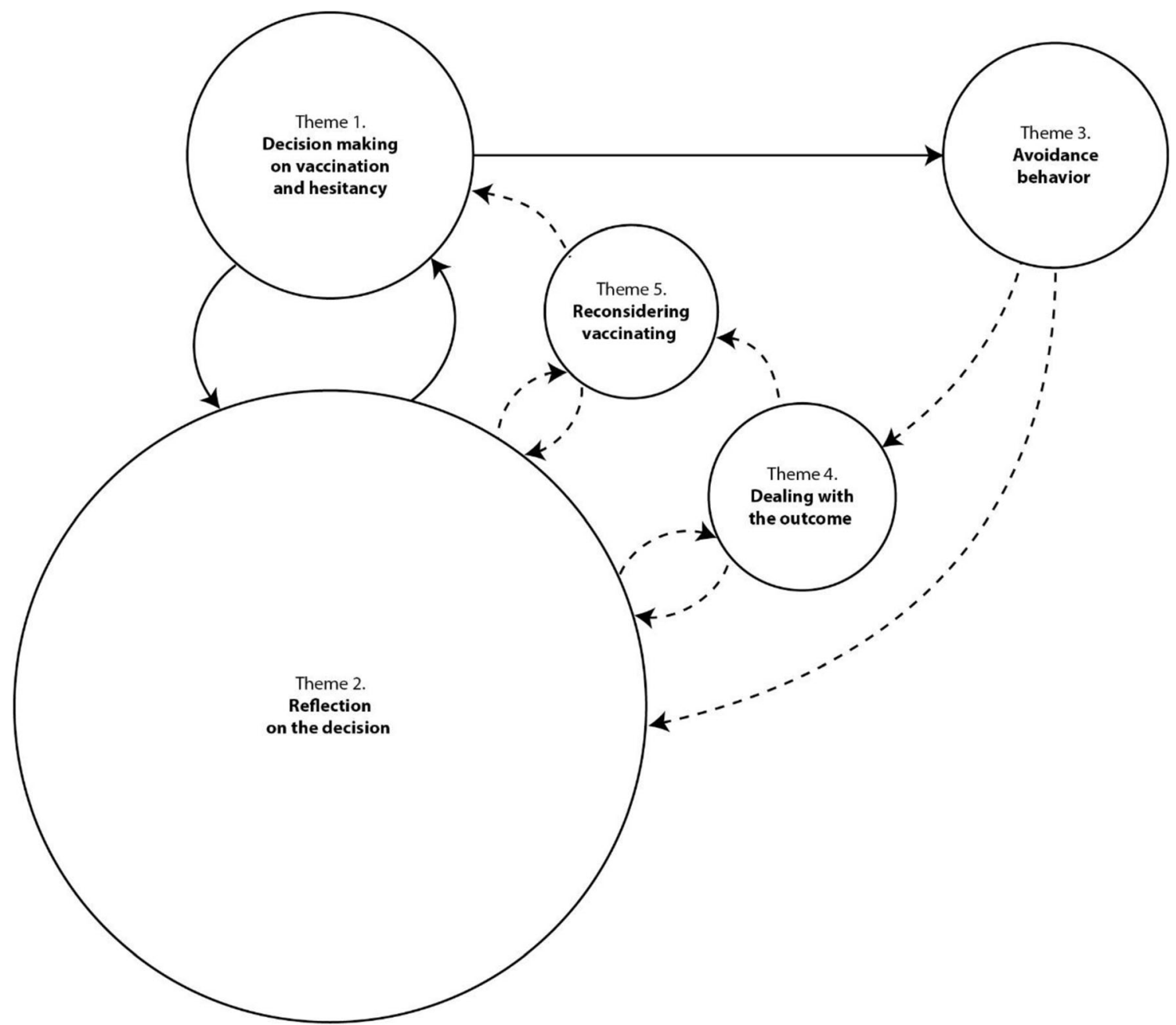

Fig. 2 Speculated relations of themes based on authors' interpretation of the data, related to parental vaccine decision making and behavior

questioning vaccination and informing themselves. Next, most of the interviews were conducted by phone which, although more practical and less expensive, represents a limitation as the interviewer lacked the opportunity to observe the participant and create a relationship of trust with them. The recruitment strategy was also susceptible to response bias and most of the participants were of high education and socioeconomic status. Although the findings may lack generalizability (which is common for qualitative research), they nevertheless provide an insight into vaccine hesitant parents' reasoning and related behavior, especially strategies of avoiding mandatory vaccination. Employing this research design provided us with a deeper understanding of this issue as well as capturing complex data rich in detail (Nowell, Norris, White, $\&$ Moules, 2017).

The obtained results provide several directions for future studies on vaccine hesitancy and avoidance. Namely, the complexity of decision making and a suggested significant role of the experientially-intuitive thinking and moral reasoning in this context may help to clarify why no completely effective ways for addressing vaccine avoidance have so far been found and points to the futility of knowledge-gap based interventions (Jarrett et al., 2015). It is well recognized that behavior based in the experiential style is much harder to change and is sensitive only to repetitive or intense experiences (Epstein et al., 1996), whereas Baron (1998) previously demonstrated the often detrimental effects of moral intuitions on public health. Since both experiential and moral positions are commonly emotionally charged, persuasion in emotional contexts works not when giving logically solid arguments but when originating new intuitions in the listener (Edwards \& von Hippel, 1995). Therefore, for future research we advise focusing on finding interventions within this framework. Next, we advise further exploration of the proposed situations in which vaccine hesitant parents may reconsider vaccinating, focusing in more detail on safety and benefits assurance that might promote vaccination, and investigating what parents would expect of the alternative vaccines. Moreover, it will be important to investigate in more detail the frequency of nonprofessional behavior of healthcare workers toward hesitant parents, as well as related group processes of stereotyping such parents. Furthermore, parents' negative experiences with 
the healthcare system should be addressed with more vigor, as the obtained results demonstrate that this is a significant trigger for entering hesitancy. Finally, our results on avoiding vaccination represent an overview of strategies parents use and merit more in-depth research on the interaction of the healthcare professionals and parents, as well as hesitancy levels in both professionals and parents.

\section{Implications for Public Policies Aimed at Increasing Vaccination Rates}

In this section we discuss the implications that the obtained results may have for public health policies. A sum of these hypothetical situations of reconsidering and other findings is also presented in Table 2 .

The obtained results confirmed the crucial role health care professionals have both in addressing vaccine hesitancy and aiding parental avoidance of scheduled immunization. Given that the health professionals influence patient vaccination uptake, it is crucial to work on better communication between patients and health professionals. Talking about potential vaccine side-effects and acknowledging adverse events when they happen may enhance a positive and trusting patientdoctor relationship in addressing issues related to vaccines. Healthcare workers should also be more mindful to the parents' period of entering the decision-making process in which they are particularly sensitive to other peoples' influences. We hypothesize this represents a crucial period during which clinicians should maximize their influence in decreasing hesitancy. Next, stronger bonds between clinicians and parents might help to identify malingering and disappearing in the system. Related to the results indicating polarization of attitudes and not perceiving the clinicians to work in the patient's best interest, it is advised to incorporate findings from social psychology in developing strategies for increasing vaccination uptake. For example, it was previously demonstrated that efficient persuasion should come from individuals which people perceive as in-group, and not out-group members (Haslam, McGarty, \& Turnes, 1996). Therefore, in designing future strategies it may be especially important to work on emphasizing the notion that the health professionals work in the child's best interest, as well as to consult literature on emotional and moral persuasion (Edwards \& von Hippel, 1995). Next, schools as institutions where immunization frequently occurs may have an important role in identifying and preventing avoidance of mandatory vaccination. For example, school staff involved in immunization may keep track of children's exemptions on scheduled vaccination and help inform physicians on the categories of parents that are at potential risk of hesitancy. Finally, as our results demonstrated that parents hold vague strategies of dealing with risk of infectious diseases, interventions might also aim at raising awareness on the futility of such strategies and parents should be educated on the objective principles on infection and methods of treating the infected.

\section{Concluding Remarks}

Overall, the results of the present study demonstrate complex and interrelated contributors to vaccine hesitancy as well as different trajectories in which people from different backgrounds reach the same decision. They suggest that vaccine hesitant parents often rely on emotions and intuition, are prone to cognitive biases and conspiracy ideation, suggesting the
Table 2 Recommendation for public health policies and it's source

\begin{tabular}{cl}
\hline Recommendation based on participants & - Assurance of vaccine safety \\
statements on reconsidering vaccination: & - Assurance of availability of alternative vaccines \\
& - Clear presentation of vaccine benefits \\
$\begin{array}{c}\text { Recommendation based on avoidance } \\
\text { strategies, and other study findings: }\end{array}$ & - Stronger and more trusting patient-doctor bonds which would \\
& minimize malingering, disappearing from the system and \\
other avoidance strategies & - Clear and trustworthy patient-doctor communication (e.g. on \\
possible side-effects) & - Sensitivity of healthcare workers regarding parents entering \\
& the decision-making process and maximizing positive social \\
& influences in this period \\
- Debriefing patients after negative experiences in healthcare \\
- Incorporating social psychology and findings from emotional \\
and moral persuasion into vaccination-promotion strategies \\
(e.g. for healthcare members to be perceived as in-group \\
members and not to label parents as anti-vaxx) \\
- Collaboration of healthcare workers with school staff \\
- Educating parents (e.g. not to rely on futile strategies in case \\
of infection)
\end{tabular}


possible importance of intuitive thinking and moral reasoning in the context of hesitancy that has direct implications for future research and strategies aimed at increasing uptake. Furthermore, the mandatory nature of immunization does not seem to be a sole sufficient strategy for addressing hesitancy, as many flaws in the patient-doctor relation were identified, especially related to triggering hesitancy and behavioral strategies of vaccination avoidance.

\section{Compliance with Ethical Standards}

\section{Conflict of Interest None to declare.}

Ethics Approval The Ethics committee of School of Medicine, University of Split, approved this study under the ID number 2181-19803-04-18-0048 and did not receive any funding. All the data was collected with respect to ethical standards according to the Declaration of Helsinki.

Informed Consent Informed consent was obtained from all individuals who participated in this study.

\section{References}

Adams, J., Bateman, B., Becker, F., Cresswell, T., Flynn, D., McNaughton, R., Oluboyede, Y., Robalino, S., Ternent, L., Sood, B. G., Michie, S., Shucksmith, J., Sniehotta, F. F., \& Wigham, S. (2015). Effectiveness and acceptability of parental financial incentives and quasy-mandatory schemes for increasing uptake of vaccinations in preschool children: A systematic review, qualitative study and discrete choice experiment. Health Technology Assessment, 19, $1-176$.

Amin, A. B., Bednarczyk, R. A., Ray, C. E., Melchiori, K. J., Graham, J., Huntsinger, J. R., \& Omer, S. B. (2017). Association of moral values with vaccine hesitancy. Nature Human Behaviour, 1(12), 873-880. https://doi.org/10.1038/s41562-017-0256-5.

Armitage, C. J., \& Conner, M. (2000). Social cognition models and health behaviour: A structured review. Psychology \& Health, 15, 173-189. https://doi.org/10.1080/08870440008400299.

Aronson, E., Wilson, T. D., Akert, R. M., \& Sommers, S. R. (2015). Social psychology. Pearson.

Baron, J. (1998). Judgment misguided: Intuition and error in public decision making. New York: Oxford University Press.

Baumeister, R. F., Tice, D. M., \& Hutton, D. G. (1989). Selfpresentational motivations and personality differences in self-esteem. Journal of Personality, 57, 547-579. https://doi.org/10. 1111/j.1467-6494.1989.tb02384.x.

Benin, A. L., Wisler-Scher, D. J., Colson, E., Shapiro, E. D., \& Homlboe, E. S. (2006). Qualitative analysis of mothers' decision-making about vaccines for infants: The importance of trust. Pediatrics, 117, 15321541. https://doi.org/10.1542/peds.2005-1728.

Blaisdell, L. L., Gutheil, C., Hootsmans, N. A. M., \& Han, P. K. (2015). Unknown risks: Parental hesitation about vaccination. Medical Decision Making, 36(4), 479-490. https://doi.org/10.1177/ $0272989 X 15607855$.

Boffey, D. (2017, September 25). HiPP to relaunch Croatian baby food item amid row over inferior products. The Guardian. Retrieved from: https:/www.theguardian.com/inequality/2017/sep/25/hippto-relaunch-croatian-baby-food-item-amid-row-over-inferiorproducts
Bozzola, E., Spina, G., Russo, R., Bozzola, M., Corsello, G., \& Villani, A. (2018). Mandatory vaccination in European countries, undocumented information, false news and the impact on vaccination uptake: The position of the Italian pediatric society. Italian Journal of Pediartics, 44, 1-4. https://doi.org/10.1189/s13052-018-0504-y.

Braun, V., \& Clarke, V. (2006). Using thematic analysis in psychology. Qualitative Research in Psychology, 3, 77-101. https://doi.org/10. 1191/1478088706qp063oa.

Brierley, J. A. (2017). The role of a pragmatist paradigm when adopting mixed methods in behavioural accounting research. International Journal of Behavioural Accounting and Finance, 6, 140-154. https://doi.org/10.1504/IJBAF.2017.10007499.

Brown, K. F., Kroll, J. S., Hudson, M. J., Ramsay, M., Green, J., Long, S. J., Vincent, C. A., Fraser, G., \& Sevdalis, N. (2010). Factors underlying parental decisions about combination childhood vaccinations including MMR: A systematic review. Vaccine, 28, 4235-4248. https://doi.org/10.1016/j.vaccine.2010.04.052.

Caron-Poulin, L., Rotondo, J., Cutler, J., Desai, S., \& Squires, S. (2017). Burden and deaths associated with vaccine preventable diseases in Canada, 2010-2014. Online Journal of Public Health Informatics, 9, e094. https://doi.org/10.5210/ojphi.v9i1.7676.

Chapman, G. B., \& Coups, E. J. (2006). Emotions and preventive health behavior: Worry, regret, and influenza vaccination. Health Psychology, 25, 82-90. https://doi.org/10.1037/0278-6133.25.1.82.

Conis, E. (2015). Vaccine nation: America's changing relationship with immunization. Chicago: University of Chicago Press.

Cruz Piqueras, M., Rodriguez Garcia de Cortazar, A., Hortal Carmona, J., \& Padilla Bernaldez, J. (2017). Vaccine hesitancy: Discourse analysis of parents who have not fully or partially vaccinated their children. Gaceta Sanitaria, 33, 53-59. https://doi.org/10.1016/j.gaceta. 2017.07.004.

Downs, J. S., Bruine de Bruin, W., \& Fischoff, B. (2008). Parents' vaccination comprehension and decisions. Vaccine, 26, 1595-1607. https://doi.org/10.1016/j.vaccine.2008.01.011.

Dube, E. (2017). Addressing vaccine hesitancy: The crucial role of healthcare providers. Clinical Microbiology and Infection, 23, 279-280. https://doi.org/10.1016/j.cmi.2016.11.007.

Dube, E., Laberge, C., Guay, M., Bramadat, P., Roy, R., \& Bettinger, J. A. (2013). Vaccine hesitancy: An overview. Human Vaccines \& Immunotherapeutics, 9, 1-11.

Dube, E., Vivion, M., \& MacDonal, N. E. (2015). Vaccine hesitancy, vaccine refusal and the anti-vaccine movement: Influence, impact and implications. Expert Review of Vaccines, 14(1), 28.

Edwards, K., \& von Hippel, W. (1995). Hearts and minds: The priority of affective versus cognitive factors in person perception. Personality and Social Psychology Bulletin, 21, 996-1011. https://doi.org/10. 1177/01461672952110001.

Epstein, S., Pacini, R., Denes-Raj, V., \& Heier, H. (1996). Individual differences in intuitive-experiential and analytical-rational thinking styles. Journal of Personality and Social Psychology, 71, 309-405. https://doi.org/10.1037/0022-3514.71.2.390.

European Centre for Disease Prevention and Control. (2015). Vaccine hesitancy among healthcare workers and their patients in Europe - A qualitative study. Stockholm: ECDC.

Falagasa, M., \& Zarkadouliaa, E. (2008). Factors associated with suboptimal compliance to vaccinations in children in developed countries: A systematic review. Current Medical Research and Opinion, 24, 1719-1741. https://doi.org/10.1185/03007990802085692.

Gardner, B., Davies, A., McAteer, J., \& Michie, S. (2010). Beliefs underlying UK parents' views towards MMR promotion interventions: A qualitative study. Psychology, Health \& Medicine, 15(2), 220230.

Gellin, B. G., Maibach, E. W., \& Marcuse, E. K. (2000). Do parents understand immunizations? A national telephone survey. Pediatrics, 106, 1097-1102. 
Gilkey, M. B., Magnus, B. E., Reiter, P. L., McRee, A. L., Dempsey, A. F., \& Brewer, N. T. (2014). The vaccination confidence scale: A brief measure of parents' vaccination beliefs. Vaccine, 32(47), 6259-6265.

Grissinger, M. (2017). Disrespectful behaviour in health care. Pharmacy \& Therapeutics, 42, 74-75.

Gullion, J. S., Henry, L., \& Gullion, G. (2008). Deciding to opt out of childhood vaccination mandates. Public Health Nursing, 25(5), 401-408.

Gust, D. A., Kennedy, A., Shui, I., Smith, P. J., Nowak, G., \& Pickering, L. K. (2005). Parent attitudes toward immunizations and healthcare providers the role of information. American Journal of Preventive Medicine, 29(2), 105-112.

Haidt, J. (2001). The emotional dog and its rational tail: A social intuitionist approach to moral judgement. Psychological Review, 108(4), 814-834. https://doi.org/10.1037//0033-295X.108.4.814.

Haslam, S., McGarty, C., \& Turnes, J. C. (1996). Salient group membership and persuasion: The role of social identity in the validation of beliefs. In J. L. Nye \& A. M. Brower (Eds.), What's social about social cognition? Research on socially shared cognition in small groups (pp. 26-56). Thousand Oaks: Sage Publications.

Haverkate, M. R., D'Acona, F., Giambi, C., Johansen, K., Lopalco, P. L., Cozza, V., \& Appelgren, E. (2012). Mandatory and recommended vaccination in the EU, Iceland and Norway: Results of the VENICE 2010 survey on the ways of implementing national vaccination programmes. European communicable disease bulletin, 17, 1-6. https://doi.org/10.2807/ese.17.22.20183-en.

Hershey, J. C., Asch, D. A., Thumasathit, T., Mezaros, J., \& Waters, V. (1994). The roles of altruism, free-riding, and bandwagoning in vaccination decisions. Organizational Behavior and Human Decision Processes, 59, 117-187.

Hobson-West, P. (2003). Understanding vaccination resistance: Moving beyond risk. Health, Risk \& Society, 3, 273-283.

Jacobson, R. M., Targonski, P. V., \& Poland, G. A. (2007). A taxonomy of reasoning flaws in the anti-vaccine movement. Vaccine, 25, 3146-3152. https://doi.org/10.1016/j.vaccine.2007.01.046.

Jarrett, C., Wilson, R., O'Leary, M., Eckersberger, E., \& Larson, H. J. (2015). Strategies for addressing vaccine hesitancy - a systematic review. Vaccine, 34, 4180-4190. https://doi.org/10.1016/j.vaccine. 2015.04.040

Larson, H. J., Cooper, L. Z., Eskola, J., Katz, S. L., \& Ratzan, S. (2011). Addressing the vaccine confidence gap. Lancet, 378, 526-535. https://doi.org/10.1016/S0140-6736(11)60678-8

Law, S. (2011). Believing bullshit: How not to get sucked into an intellectual black hole. New York: Prometheus Books.

Loewenstein, G.F., Weber, U.E., Hsee. C.K., Welch, N. (2001). Risk as Feelings. Psychological Bulletin, 127, 267-86.

Meszaros, J., Asch, D. A., Baron, J., Hershey, J. C., Kunreuther, H., \& Schwartz-Buzaglo, J. (1996). Cognitive processes and the decisions of some parents to forego pertussis vaccination for their children. Journal of Clinical Epidemiology, 49, 697-703.

Mills, E., Jadad, A. R., Ross, C., \& Wilson, K. (2005). Systematic review of qualitative studies exploring parental beliefs and attitudes toward childhood vaccination identifies common barriers to vaccination. Journal of Clinical Epidemiology, 58, 1081-1088. https://doi.org/ 10.1016/j.jclinepi.2005.09.002.

Nowell, L. S., Norris, J. M., White, D. E., \& Moules, N. J. (2017). Thematic analysis: Striving to meet the trustworthiness criteria. International Journal of Qualitative Methods, 16, 1-13. https:// doi.org/10.1177/1609406917733847.

O'Brien, B. C., Harris, I. B., Beckman, T. J., Reed, D. A., \& Cook, D. A. (2014). Standards for reporting qualitative research: A synthesis of recommendation. Academic Medicine, 89, 1245-1251. https://doi. org/10.1097/ACM.0000000000000388.

Omer, S. B., Slamon, D. A., Orenstein, W. A., deHart, M. P., \& Halsey, N. (2009). Vaccine refusal, mandatory immunization, and the risks of vaccine- preventable diseases. New England Journal of Medicine, 360(19), 1981-1988.

Patton, M. (1990). Qualitative evaluation and research methods. Beverly Hills: SAGE

Peterson, P., Meurice, F., Stanberry, L. R., Glismann, S., Rosenthal, S. L., \& Larson, H. J. (2016). Vaccine hesitancy and healthcare providers. Vaccine, 34, 6700-6706. https://doi.org/10.1016/j.vaccine.2016.10. 042.

Prislin, R., Dyer, J. A., Blakely, C. H., \& Johnson, C. D. (1998). Immunization status and sociodemographic characteristics: The mediating role of beliefs, attitudes, and perceived control. American Journal of Public Health, 88(12), 1821-1826.

Prislin, R., Suarez, L., Simpton, D. M., \& Dyer, J. A. (1998). When acculturation hurts: The case of immunization. Social Science and Medicine, 47(12), 1947-1956.

Prooijen, J. W., \& Douglas, K. (2018). Belief in conspiracy theories: Basic principles of an emerging research domain. European Journal of Social Psychology, 48, 897-908. https://doi.org/10. 1002/ejsp.2530.

Salmon, D. A., Moulton, L. H., Omer, S. B., DeHart, M. P., Stokley, S., \& Halsey, N. A. (2005). Factors associated with refusal of childhood vaccines among parents of school-aged children: A case-control study. Archives of Pediatrics and Adolescent Medicine, 159, 470 476.

Sandelowski, M. (1995). Focus on qualitative methods sample size in qualitative research. Research in Nursing and Health, 18, 179-183.

Smith, L. E., Amlot, R., Weinman, J., Yiend, J., \& Rubin, J. G. (2017). A systematic review of factors affecting vaccine uptake in young children. Vaccine, 35, 6059-6069. https://doi.org/10.1016/j.vaccine. 2017.09.046.

Smith, P. J., Chu, S. Y., \& Barker, L. E. (2004). Children who have received no vaccines: Who are they and where do they live? Pediatrics, 114(1), 187-195.

Sobo, E. J. (2016). What is herd immunity, and how does it relate to pediatric vaccination uptake? US parent perspectives. Social Science and Medicine, 165, 187-195. https://doi.org/10.1016/j. socscimed.2016.06.015.

Stewart, K., Wyatt, R., \& Conway, J. (2011). Unprofessional behaviour and patient safety. The International Journal of Clinical Leadership, 17, 93-101.

Strauss, A., \& Corbin, J. (1998). Basics of qualitative research. Thousand Oaks: SAGE Publications.

Streefland, P., Chowdhury, A. M. R., \& Ramos-Jimenez, P. (1999). Patterns of vaccination acceptance. Social Science and Medicine, 49, 1705-1716.

Suter, R. S., Pachur, T., \& Hertwig, R. (2015). How affect shapes risky choice: Distorted probability weighting versus probability neglect. Journal of Behavioural Decision Making., 29, 437-449. https://doi. org/10.1002/bdm.1888.

Suter, R. S., Pachur, T., Hertwig, R., Endestad, T., \& Biele, G. (2015). The neural basis of risky choice with affective outcomes. PLoS One, 10, e0122475. https://doi.org/10.1371/journal.pone.0122475.

Swami, V., Voracek, M., Stieger, S., Tran, U. S., \& Furnhan, A. (2014). Analytic thinking reduces belief in conspiracy theories. Cognition, 133, 572-585. https://doi.org/10.1016/j.cognition.2014.08.006.

Taylor, M. D., Hart, C. L., Davey Smith, G., Starr, J. M., Whalley, L. J., $\&$ al., e. (2003). Childhood mental ability and smoking cessation in adulthood: Prospective observational study linking the Scottish mental survey 1932 and the Midspan studies. Journal of Epidemiology Community Health, 57, 464-465.

Tomljenovic, H., Bubic, A., \& Erceg, N. (2019). It just doesn't feel right the relevance of emotions and intuition for parental vaccine conspiracy beliefs and vaccination uptake. Psychology \& Health, 17, 538554. https://doi.org/10.1080/08870446.2019.1673894.

Wei, F., Mullooly, J. P., Goodman, M., et al. (2009). Identification and characteristics of vaccine refusers. BMC Pediatrics, 9-18. 
WHO. (2018a). Europe observes a 4-fold increase in measles cases in 2017 compared to a previous year. Press release Retrieved from: https://www.euro.who.int/en/media-centre/sections/press-releases/ 2018/europe-observes-a-4-fold-increase-in-measles-cases-in-2017compared-to-previous-year.

WHO. (2018b). Measles cases hit record high in the European region. Press release Retrieved from: https://www.euro.who.int/en/mediacentre/sections/press-releases/2018/measles-cases-hit-record-highin-the-european-region.

WHO. (2019). Ten threats to global health in 2019. Press release Retrieved from: https:/www.who.int/news-room/spotlight/tenthreats-to-global-health-in-2019.
Wolfe, R. M., Sharp, L. K., \& Lipsky, M. S. (2002). Content and design attributes of antivaccination web sites. JAMA, 287, 3245-3248.

Yaqub, O., Castle-Clarke, S., Sevdalis, N., \& Chataway, J. (2014). Attitudes to vaccination: a critical review. Social Science and Medicine, 112, 1-11. https://doi.org/10.1016/j.socscimed.2014.04. 018.

Publisher's Note Springer Nature remains neutral with regard to jurisdictional claims in published maps and institutional affiliations. 